\section{Effects of Dynamic Annular Shape Changes on Mitraclip Therapy and Combining Mitral Cerclage Annuloplasty}

\section{To the Editor:}

Chan et $\mathrm{al}^{1}$ highlight the outcomes of Mitraclip therapy. During diastole, the shape of the mitral annulus is roughly circular, but during systole the annulus becomes kidney-shaped with an anteroposterior (septolateral) diameter that is smaller than the transverse diameter. A $26 \pm 3 \%$ reduction of the mitralorifice area during systole results from the displacement of the aortomitral curtain towards the center of the orifice. ${ }^{2}$ Because the Mitraclip is deployed in the systolic phase of the cardiac cycle, there will be increased tension force over the clipped part in an anterior-posterior direction during diastole. Increased tension over the clipped parts of both leaflets may cause clip detachment. In the Everest I study, "partial clip detachment" occurred in 10 patients (9\%). ${ }^{3}$ Although it was stated in the Everest II study report that "no device embolization occurred", how many clips were detached was not reported.

Nielsen et al demonstrated in an experimental study that tension over the Alfieri stitch is maximal in the diastolic phase of cardiac cycle and is determined by septolateral dimension changes during the cardiac cycle. ${ }^{4}$ Similar considerations should apply to the Mitraclip.

The physiological feature of "dynamic annular shape changes in systole and diastole" may cause increased tension force over the Mitraclip during diastole, which is the reason why the mitral annuloplasty should be fixed in the systolic shape.

As a result, "partial clip detachment", "clip embolization", "posterior or anterior leaflet laceration", "new onset of mitral regurgitation in patients who have been treated successfully with mitraclip deployment previously" may be considered as technical insufficiencies of Mitraclip therapy without annuloplasty. This concept may suggest that the long-term durability of Mitraclip therapy (without annuloplasty ring) may not be as good as expected. Nonetheless, it can be used in patients who refuse surgical treatment and in those considered inoperable. In further investigations, Mitraclip therapy may be combined with mitral cerclage annuloplasty ${ }^{5}$ to fix the mitral annulus in the systolic position to reduce the tension force over the clip. This concept may contribute to further improvement in clinical outcomes.

\section{References}

1. Chan PH, She HL, Alegria-Barrero E, Moat N, Di Mario C, Franzen O. Real-world experience of MitraClip for treatment of severe mitral regurgitation: Compromise between mitral regurgitation reduction and maintenance of adequate opening area. Circ J 2012; 76: 24882493.

2. Carpentier A, Adams DH, Filsoufi F. Surgical anatomy and phsiology. In: Carpentier A, Adams DH, Filsoufi F, editors. Carpentier's reconstructive valve surgery. Philadelphia: Saunders, 2010; 27-43.

3. Feldman T, Kar S, Rinaldi M, Fail P, Hermiller J, Smalling R, et al. Percutaneous mitral repair with the MitraClip system: Safety and midterm durability in the initial EVEREST (Endovascular Valve Edgeto-Edge REpair Study) cohort. J Am Coll Cardiol 2009; 54: 686694.

4. Nielsen SL, Timek TA, Lai DT, Daughters GT, Liang D, Hasenkam JM, et al. Edge-to-edge mitral repair tension on the approximating suture and leaflet deformation during acute ischemic mitral regurgitation in the ovine heart. Circulation 2001; 104(Suppl I): I-29-I-35.

5. Kim JH, Kocaturk O, Ozturk C, Faranesh AZ, Sonmez M, Sampath S, et al. Mitral cerclage annuloplasty, a novel transcatheter treatment for secondary mitral valve regurgitation: Initial results in swine. $J$ Am Coll Cardiol 2009; 54: 638-651.

Murat Tavlasoglu, MD

Department of Cardiovascular Surgery, Diyarbakir Military Medical Hospital,

Diyarbakir, Turkey

Ahmet Baris Durukan, MD

Cardiovascular Surgery,

Medicana International Ankara Hospital,

Ankara, Turkey

Celalettin Gunay, MD

Faruk Cingoz, MD

Department of Cardiovascular Surgery, Gulhane Military Medical Hospital, Ankara, Turkey

(Released online December 27, 2012) 